\title{
Frequency of Genotype With $\triangle$ F508 Mutation in CFTR Gene Among Iranian Cystic Fibrosis Patients With Pancreatic Insufficiency
}

\author{
Ahmad Khodadad, ${ }^{1,2,}$ Elaheh Elahi, ${ }^{3}$ Setareh Sadat Bani Hassani, Pejman Rouhani, Bamdad \\ Sadeghi, ${ }^{4}$ and Nima Rezaei ${ }^{4,5,6}$ \\ ${ }^{1}$ Children's Medical Center, Pediatric Center of Excellence, Tehran University of Medical Sciences, Tehran, IR Iran \\ ${ }^{2}$ Department of Pediatrics, Tehran University of Medical Sciences, Tehran, IR Iran \\ ${ }_{4}^{3}$ School of Biology, College of Science, University of Tehran, Tehran, IR Iran \\ ${ }_{5}^{4}$ Research Center for Immunodeficiencies, Children's Medical Center, Tehran University of Medical Sciences, Tehran, IR Iran \\ 5 Research Center for Immunodeficiencies, Children's Medical Center, Tehran University of Medical Scien \\ ${ }^{6}$ Department of Immunology, School of Medicine, Tehran University of \\ *Corresponding author: Ahmad Khodadad, Children's Medical Center, Pediatric Center of Excellence, Tehran University of Medical Sciences, Tehran, IR Iran. Tel: +98-2166929234, \\ Fax:+98-2166929235, E-mail: khodadadmd@yahoo.com
}

Received 2015 July 5; Accepted 2015 August 22

\begin{abstract} worldwide. phenotype of Iranian patients with CF. were checked.

Keywords: Cystic Fibrosis, $\Delta$ F508 Mutation, Genotype, Phenotype

\section{Background}

Cystic fibrosis (CF) is the most prevalent severe genetic disorder in western countries, with an incidence rate of 1 in 2,000 to 4,000 births (1). CF is a heterogeneous disease with variable signs and symptoms (2-5). Variation and distribution of mutations in the CFTR (cystic fibrosis transmembrane conducting regulator) gene along with environmental factors are effective in multiple organs damage. It seems that $\Delta \mathrm{F} 508$ is the most frequent mutation, which occurs in $70 \%$ of CF patient chromosomes worldwide (6). $\Delta \mathrm{F} 508$ causes the most severe and lethal form CF disease.
\end{abstract}

Background: Cystic fibrosis (CF) is the most prevalent lethal autosomal recessive disease with a broad spectrum of phenotypes. Mutation of $\triangle F 508$ in the CFTR gene is the most important and lethal mutation in $\mathrm{CF}$, which contains $70 \%$ of all predisposing mutations for $\mathrm{CF}$

Objectives: Determining frequency of genotypes with $\triangle \mathrm{F} 508$ mutation in CFTR gene, and evaluation of correlation between genotype and

Patients and Methods: Thirty six patients were included in this cross sectional study. $\Delta$ F508 mutations in both alleles of the CFTR gene

Results: Among 36 pediatric patients, $\Delta \mathrm{F} 508$ mutation was detected in $9(25 \%)$ patients; 2 patients were heterozygous, and 7 patients homozygous for this mutation. From overall 72 tracked alleles, $11(15.2 \%)$ were found to have $\Delta$ F508 mutations. Differences in prevalence of dyspnea and bronchiectasis were significant in homozygote group, compared with non-mutated group for $\Delta$ F508.

Conclusions: It seems that more $\triangle \mathrm{F} 508$ mutated alleles lead to more severe symptoms of $\mathrm{CF}$.

\section{Objectives}

Determining frequency of genotypes with $\triangle \mathrm{F} 508$ mutation in CFTR gene, and evaluation of correlation between genotype and phenotype of Iranian patients with CF.

\section{Patients and Methods}

In this cross sectional study, 36 documented CF patients (17 males and 19 females), aged 2 to 42 months, with domi- nant phenotype of pancreas insufficiency (PI) who regularly attended Children's Medical Center in Tehran were investigated. The inclusion criteria for Pancreas Insufficiency (PI) were defined as two positive results of sweat test and history of steatorrhea confirmed by detecting fat drops in stool examinations. Demographic data, along with clinical, paraclinical and radiologic features which represent the spectrum of phenotypes were obtained by hospital documents and questionnaires designed for the study. Blood samples of 1-2 cc volumes were provided from each patient and DNA was extracted and examined for genetic assays to detect $\triangle F 508$ mutation of each allele of CFTR.

\section{Results}

Assessment of 36 patients with mutant primer showed that 9 were identified to have deletion mutations of $\Delta$ F508. Then, all samples were investigated for homozygosity with normal primer in which from all patients, 34 had one normal allele. 7 were heterozygotes, and 2 were

Copyright (C) 2015, Growth \& Development Research Center. This is an open-access article distributed under the terms of the Creative Commons Attribution-NonCommercial 4.0 International License (http://creativecommons.org/licenses/by-nc/4.0/) which permits copy and redistribute the material just in noncommercial usages, provided the original work is properly cited. 
homozygous for $\Delta \mathrm{F} 508$ mutation. At last, from 72 studied alleles, 11 were found affected by $\Delta \mathrm{F} 508$ mutation. Patients were classified into 3 groups by genotypes: homozygous for $\Delta \mathrm{F} 508$ (5.5\%), heterozygotes (19.4\%) and non-mutated by $\Delta \mathrm{F} 508$ ( $75 \%)$. In this study, all patients had FTT (Fail to Thrive) with a growth percentile curve of fewer than $3 \%$ or depletion of growth curve more than 2 curves in growth percentile chart. In patients with positive pharyngeal culture, organisms were as follow: Pseudomonas aeroginosa, streptococcus group A, Staphylococcus aurous, Klebsiella and Candida.

The frequency of various clinical presentations categorized by genotypes is shown for all patients (except in one with incomplete medical document) in Table 1. Dyspnea was one of the clinical symptoms with different correlations in different genotype. In homozygous patients for $\Delta$ F508 mutations compared with those not affected by $\triangle \mathrm{F} 508$, dyspnea was significantly more prominent (P $=0.049$ ). Frequency of bronchiectasis in homozygotes group was also significantly higher than in non-mutated subjects $(\mathrm{P}=0.015)$, while this rate was significantly higher in heterozygotes in comparison with non-mutated group $(\mathrm{P}=0.043)$. Quantitative comparison of sweat chloride concentration in homozygotes group with non-mutated group showed significant difference $(P=0.012)$, but this significance was not the same between homozygotes and heterozygotes group for $\Delta \mathrm{F} 508$ mutation $(\mathrm{P}=0.1$ ), and between heterozygotes and non-mutated groups ( $P$ $=0.213)$. Fatty droplets in stool exam were significantly more numerous in homozygotes group for $\Delta \mathrm{F} 508$ than others $(P=0.022)$, but there were no significant difference of droplets number between homozygotes and heterozygotes group, and heterozygotes with non-mutated $\Delta \mathrm{F} 508(\mathrm{P}=0.088$ and $\mathrm{P}=0.516$, respectively $)$.

Table 1. Clinical Manifestations of All Patients and Respected to $\triangle$ f508 Mutation Genotypes

\begin{tabular}{|c|c|c|c|c|c|c|c|c|c|c|c|c|}
\hline \multirow[t]{2}{*}{$\begin{array}{l}\text { Clinical } \\
\text { Manifestations }\end{array}$} & \multicolumn{3}{|c|}{$\begin{array}{c}\text { Presence of } \\
\text { signs/symptoms }\end{array}$} & \multirow{2}{*}{ 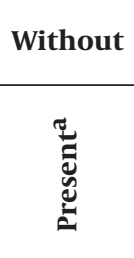 } & \multicolumn{2}{|c|}{$\Delta$ F508 Mutation } & \multicolumn{3}{|c|}{ Heterozygous for $\Delta$ F508 } & \multicolumn{3}{|c|}{ Homozygote for $\Delta \mathrm{F} 508$} \\
\hline & 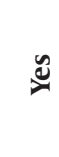 & $\stackrel{0}{z}$ & 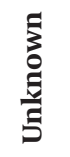 & & 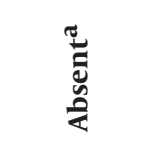 & 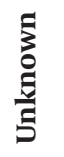 & 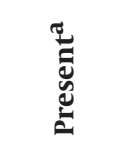 & 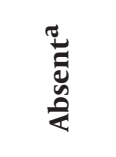 & 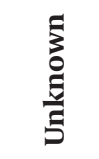 & 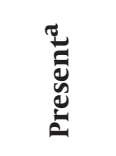 & 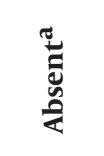 & 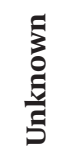 \\
\hline Cough & 32 & 3 & 1 & $24(92.3)$ & $2(7.7)$ & 1 & $7(100)$ & 0 & 0 & $1(50)$ & $1(50)$ & 0 \\
\hline Dyspnea & 15 & 20 & 1 & $8(30.8)$ & $18(69.2)$ & 1 & $5(71.4)$ & $2(28.6)$ & 0 & $2(100)$ & 0 & 0 \\
\hline Bronchitis & 2 & 33 & 1 & $1(3.8)$ & $25(96.2)$ & 1 & $1(14.3)$ & $6(85.7)$ & & $2(100)$ & 0 & 0 \\
\hline Bronchiectasia & 4 & 31 & 1 & $1(3.8)$ & $25(96.2)$ & 1 & $2(28.6)$ & $5(71.4)$ & 0 & $1(500)$ & $1(50)$ & 0 \\
\hline Bronchiolitis & 2 & 33 & 1 & 0 & $26(100)$ & 1 & $2(28.6)$ & $5(71.4)$ & 0 & 0 & $2(100)$ & 0 \\
\hline Pneumonia & 22 & 13 & 1 & $14(53.8)$ & $12(46.3)$ & 1 & $7(100)$ & 0 & 0 & $1(50)$ & $1(50)$ & 0 \\
\hline Diarrhea & 7 & 28 & 1 & $4(15.4)$ & $22(84.6)$ & 1 & $2(28.6)$ & $5(71.4)$ & 0 & $1(50)$ & $1(50)$ & 0 \\
\hline Edema & 7 & 28 & 1 & $5(19.2)$ & $21(80.8)$ & 1 & $1(14.3)$ & $6(85.7)$ & 0 & $1(50)$ & $1(50)$ & 0 \\
\hline Anemia & 10 & 12 & 14 & $9(56.2)$ & $7(43.8)$ & 11 & $1(20)$ & $4(80)$ & 2 & 0 & $1(100)$ & 1 \\
\hline $\begin{array}{l}\text { Total Hyperbilirubi- } \\
\text { nemia }\end{array}$ & 3 & 28 & 5 & $2(9.1)$ & $20(90.9)$ & 5 & 0 & $7(100)$ & 0 & $1(50)$ & $1(50)$ & 0 \\
\hline $\begin{array}{l}\text { Direct Hyperbilirubi- } \\
\text { nemia }\end{array}$ & 3 & 28 & 5 & $2(9.1)$ & $20(90.9)$ & 5 & 0 & $7(100)$ & 0 & $1(50)$ & $1(50)$ & 0 \\
\hline Salt kiss & 11 & 5 & 20 & $10(71.4)$ & $4(28.6)$ & 13 & $1(50)$ & $1(50)$ & 5 & 0 & 0 & 2 \\
\hline Ascitis & 1 & 29 & 6 & $1(4.5)$ & $21(95.5)$ & 5 & 0 & $6(100)$ & 1 & 0 & $2(100)$ & 0 \\
\hline Reflux & 10 & 19 & 7 & $6(30)$ & $14(70)$ & 7 & $3(42.9)$ & $4(57.1)$ & 0 & $1(50)$ & $1(50)$ & 0 \\
\hline Hyperinflation in CXR & 16 & 14 & 6 & $10(47.6)$ & $11(52.4)$ & 6 & $4(42.9)$ & $3(57.1)$ & 0 & $2(100)$ & 0 & 0 \\
\hline Vomiting & 12 & 20 & 4 & $13(53.5)$ & $10(43.5)$ & 4 & $2(28.6)$ & $5(71.4)$ & 0 & 0 & $2(100)$ & 0 \\
\hline Hypokalemia & 13 & 19 & 4 & $11(40.7)$ & $12(52.2)$ & 4 & $5(71.4)$ & $2(28.6)$ & 0 & 0 & $2(100)$ & 0 \\
\hline Hypernatremia & 13 & 19 & 4 & $11(47.8)$ & $12(52.2)$ & 4 & $2(28.6)$ & $5(71.4)$ & 0 & 0 & $2(100)$ & 0 \\
\hline Metabolic alkalosis & 14 & 18 & 4 & $12(44.4)$ & $11(40.7)$ & 4 & $2(28.6)$ & $5(71.4)$ & 0 & 0 & $2(100)$ & 0 \\
\hline Organomegaly & 8 & 24 & 4 & $7(30.4)$ & $16(69.6)$ & 4 & 0 & $7(100)$ & 0 & $1(50)$ & $1(50)$ & 0 \\
\hline
\end{tabular}

${ }^{\mathrm{a}}$ Data are presented as No. (\%). 


\section{Discussion}

This study was conducted regarding the necessity of detecting genetic mechanisms interacting in pathogenesis of $\mathrm{CF}$, and description of phenotypes in relation to underlying genotypes. Frequency of $\Delta \mathrm{F} 508$ in our patients with PI was 11 (15.2\%) from all 72 alleles studied. This value was comparable with data of previous reports on CF prevalence in Iran without considering special related phenotypes (7-9). In correlation of clinical phenotypes with the genotype groups, frequency of dyspnea in homozygotes for $\Delta \mathrm{F} 508$ was documented significantly higher than in heterozygotes and non-mutated groups for $\Delta \mathrm{F} 508$. Bronchiolitis was found more prevalent in heterozygote group than others; and bronchiectasis was also more significantly prevalent in heterozygous and homozygous patients for $\Delta \mathrm{F} 508$ mutations compared with non-mutated ones. The results of our research in agreement with other studies clarifies that the more $\Delta$ F508 mutation affects alleles, the more respiratory complications are accompanied with genotype (10).

\section{References}

1. Morral N, Bertranpetit J, Estivill X, Nunes V, Casals T, Gimenez J, et al. The origin of the major cystic fibrosis mutation (delta F508) in European populations. Nat Genet. 1994;7(2):169-75. doi: 10.1038/ng0694-169. [PubMed: 7920636]

2. Jameson JL. Principles of Molecular Medicine. Humana Pr; 1998.
3. Farahmand F, Khalili M, Shahbaznejad L, Hirbod-Mobarakeh A, Najafi Sani M, Khodadad A, et al. Clinical presentation of cystic fibrosis at the time of diagnosis: a multicenter study in a region without newborn screening. Turk J Gastroenterol. 2013;24(6):5415. [PubMed: 24623294]

4. Najafi M, Alimadadi H, Rouhani P, Kiani MA, Khodadad A, Motamed $\mathrm{F}$, et al. Genotype-phenotype relationship in Iranian patients with cystic fibrosis. Turk J Gastroenterol. 2015;26(3):241-3. doi:10.5152/tjg.2015.5945. [PubMed:26006199]

5. Fallahi G, Najafi M, Farhmand F, Bazvand F, Ahmadi M, Ahmadi F, et al. The clinical and laboratory manifestations of Iranian patients with cystic fibrosis. Turk J Pediatr. 2010;52(2):132-8. [PubMed: 20560247]

6. Estivill X, Bancells C, Ramos C. Geographic distribution and regional origin of 272 cystic fibrosis mutations in European populations. Human Mut. 1997;10(2):135-54. doi: 10.1002/(sici)10981004(1997)10:2<135::aid-humu6>3.3.co;2-p.

7. Elahi E, Khodadad A, Kupershmidt I, Ghasemi F, Alinasab B, Naghizadeh R, et al. A haplotype framework for cystic fibrosis mutations in Iran. J Mol Diagn. 2006;8(1):119-27. doi: 10.2353/ jmoldx.2006.050063. [PubMed:16436643]

8. Jalalirad M, Houshmand M, Mirfakhraie R, Goharbari MH, Mirzajani F. First study of CF mutations in the CFTR gene of Iranian patients: detection of DeltaF508, G542X, W1282X, A120T, R117H, and R347H mutations. J Trop Pediatr. 2004;50(6):359-61. doi: 10.1093/ tropej/50.6.359. [PubMed:15537723]

9. Alibakhshi R, Kianishirazi R, Cassiman JJ, Zamani M, Cuppens H. Analysis of the CFTR gene in Iranian cystic fibrosis patients: identification of eight novel mutations. J Cyst Fibros. 2008;7(2):102-9. doi:10.1016/j.jcf.2007.06.001. [PubMed:17662673]

10. Eaton TE, Weiner Miller P, Garrett JE, Cutting GR. Cystic fibrosis transmembrane conductance regulator gene mutations: do they play a role in the aetiology of allergic bronchopulmonary aspergillosis? Clin Exp Allergy. 2002;32(5):756-61. doi: 10.1046/j.13652222.2002.01361.x.[PubMed:11994102] 